\title{
Preface: Crossing disciplinary borders in rotifer research
}

\author{
Proceedings of the 15th International Rotifer Symposium
}

\author{
Elizabeth J. Walsh (i) Robert L. Wallace $\mathbb{D}$
}

Received: 9 September 2019/Revised: 19 September 2019/Accepted: 28 September 2019/Published online: 29 October 2019 (C) Springer Nature Switzerland AG 2019

In August of 1974 at the 19th Congress of the Societas Internationalis Limnologiae (Winnipeg, Canada), a small group of aquatic scientists led by Dr. Agnes Ruttner-Kolisko proposed an innovative concept: a special symposium dedicated solely to rotifer research should be held. Two years later, in late September, Agnes hosted the first International Rotifer Symposium (IRS) at the research station located on Lunzer Untersee (Lunz am See, Austria). Every 3 years since that inaugural meeting, the "rotifer family" has convened somewhere in the world to share research on all topics related to rotifer biology. Accordingly, the IRS comprises scientists who devote most, if not all, of their time to research on the biology, ecology, systematics, and evolution of rotifers, or who find rotifers to be useful model systems to explore other

The contributions of the XVth International Rotifer Symposium are dedicated to the memory of María Rosa Miracle

Guest editors: Steven A. J. Declerck, Diego Fontaneto, Rick Hochberg \& Terry W. Snell / Crossing Disciplinary Borders in Rotifer Research

\section{E. J. Walsh $(\bowtie)$}

Department of Biological Sciences, The University of Texas at El Paso, El Paso, TX, USA

e-mail: ewalsh@utep.edu

R. L. Wallace

Department of Biology, Ripon College, Ripon, WI, USA interesting lines of inquiry. Yet these meetings do more than just share research, they inspire others to pursue a deeper appreciation of these remarkable small metazoans.

The 15th IRS was held on the campus of The University of Texas at El Paso, Texas (UTEP) from the 3rd to 9th of June 2018. Attendees included just over 100 participants and accompanying persons from 17 countries (Fig. 1), with the highest representation from the USA (38), Mexico (26), and Europe (15). Sponsors for the meeting included UTEP's College of Science, Border Biomedical Research Center, Office of Research and Sponsored Projects, and Dodson Funds. Additional funds for workshops and student awards were provided by Springer ${ }^{\circledR}$, Proceedings of the Biological Society of Washington, Leica ${ }^{\circledR}$, and Zeiss ${ }^{\circledR}$. The Scientific and Local Organizing Committees were responsible for planning, assembling, and executing the conference. The Scientific Committee comprised Steven Declerck, Holger Herlyn, Rick Hochberg, Linda May, S. Nandini, Roberto RicoMartínez, S. S. S. Sarma, Terry Snell, Bob Wallace, and Liz Walsh; the Local Organizing Committee included Mitzel Aveytia, Carl Lieb, Judith Ríos Arana, Nazia Sharmin, Bob Wallace, and Liz Walsh.

The meetings opened with a reception at the Centennial Museum and Chihuahuan Desert Gardens on the UTEP campus. With both permanent and rotating exhibits, the Centennial Museum-the oldest 

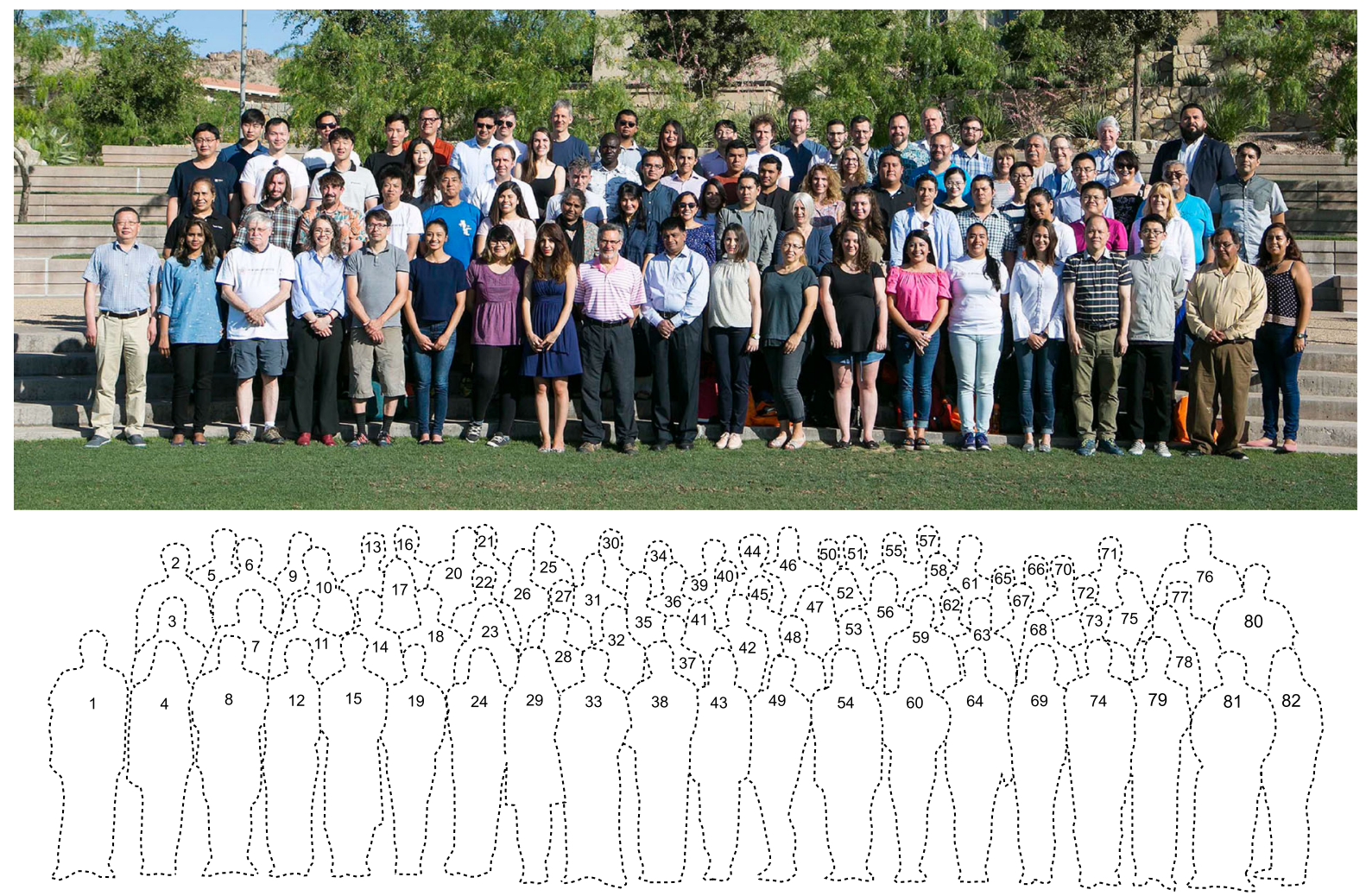

Fig. 1 Participants of the XVth International Rotifer Symposium. 1. Jiaxin Yang; 2. Wen Xinli; 3. Judith Ríos Arana; 4. Nazia Sharmin; 5. Young Hwan Lee; 6. Hui Yang; 7. Patrick Brown; 8. Robert Wallace; 9. Min-Chul Lee; 10. Jeonghoon Han; 11. Rick Hochberg; 12. Bette Hecox-Lea; 13. Chang-Bum Jeong; 14. Tomotake Wada; 15. Claus-Peter Stelzer; 16. Brian Dingmann; 17. Hye-Min Kang; 18. Atsushi Hagiwara; 19. Cynthia-Rae Moreno; 20. Jorge Ciros-Pérez; 21. Dzmitry Lukashanets; 22. Andrew Schurko; 23. Jillian Serrano; 24. Gabriela Hurtado; 25. Steven Declerck; 26. Ivana Jezkova; 27. Manuel Serra; 28. Nandini Sarma; 29. Azar Kordbacheh; 30. Marco Antonio Jiménez Santos; 31. Robert Nesta Kagali; 32. Maria Špoljar; 33. Terry Snell; 34. Brenda Karen González Pérez; 35. José Antonio Guevara-Franco; 36. Adán Jiménez Nigó; 37. Ligia Rivera De la Parra; 38. S.S.S. Sarma; 39. Gen Kaneko; 40. Uriel Arreguin-Rebolledo; 41. Rosa Martha Moreno Gutíerrez; 42. Cesar Alejandro Zamora-Barrios; 43.

in El Paso-celebrates natural and cultural history of the bi-national community in this region of the Chihuahuan Desert. During the week of the symposium, a small exhibit on rotifer jaws by Wallace, Walsh, and Hochberg was on display. The special friendship that UTEP shares with the country of Bhutan is very evident in the Bhutanese-inspired architecture of university buildings and in the handcarved and hand-painted Lhakhang building.
Georgia Stamou; 44. Diego Fontenato; 45. Miguel Hernandez Pedraza; 46. David Mark Welch; 47. Sofia Paraskevopoulou; 48. Linda May; 49. Evangelia Michaloudi; 50. Pierluigi Colangeli; 51. Holger Herlyn; 52. Kristin Gribble; 53. Aikaterini Karagianni; 54. Claudia Tausz; 55. Andreas Fröbius; 56. Jesús Alvarado Flores; 57. Guntram Weithoff; 58. Jonathon Mohl; 59. Gerardo Guererro Jiménez; 60. Daniela Pérez-Yañez; 61. Joe Connolly; 62. Yun Li; 63. Enrique García; 64. Jovana ArroyoCastro; 65. Lara Barnes; 66. Jose Luis Gama Flores; 67. Diwen Liang; 68. Susana Saucedo Ríos; 69. Marcela Rivero Estens; 70. Peter Starkweather; 71. John Gilbert; 72. Nan Wei; 73. Qing Wang; 74. Shuyu Gu; 75. Maribel Baeza; 76. Sergio Samaniego; 77. Marcelo Silva-Briano; 78. Liz Walsh; 79. Jian Tian; 80. Cristian Espinosa Rodríguez; 81. Roberto Rico-Martínez; 82. Gabriela Alvarado-Suárez; Not pictured: Omar Amin; Elana Lebario; Alan Munoz; Javier Ordoñez; Diego Reyes; Jose A. Rivas Jr.; Ashanti Shapiro; Robert Walsmith

During the mid-conference excursion on Wednesday, the participants visited White Sands National Monument in New Mexico. Located in the heart of the Tularosa Basin - a graben in the Basin and Range Province - the monument preserves a unique $>700$ $\mathrm{km}^{2}$ region of desert soil crusts, as well as the world's largest gypsum dunes field and Lake Lucero, a large temporary playa, which was dry at the time of our visit (Fig. 2). The conference ended on Friday evening with 
a closing dinner featuring authentic Texas-Mexican cuisine and a local mariachi band. On the Saturday after the conference, some of the symposium participants visited Carlsbad Caverns National Park (New Mexico). Visitors who descended to the base of the caverns $(\sim 225 \mathrm{~m})$ had two options: a direct elevator or a walk along a paved path of $\sim 2 \mathrm{~km}$. This stunning sample of subterranean, karst topography yielded countless opportunities to photograph stalactites and stalagmites (Fig. 3).

On Monday and Wednesday evenings, several workshops were held including: "Delimiting species within the Brachionus plicatilis complex," "Writing for clarity, economy, and precision," and "How to make an offer to host an International Rotifer Symposium." Poster sessions were held on Tuesday (Ecology and Genomic Approaches) and Thursday (Applied Research and Evolution).

The winner of the award for best student presentation was Jose A. Rivas, Jr. for his talk entitled "Dust storms and the transport of rotifers in the Chihuahuan Desert." Other winners included Pierluigi Colangeli and Sofia Paraskevopoulou. Student poster winners were Ivana Jezcova, Robert Nestor Kagali, and Elizabeth Preza. The winning image of the photo contest was a confocal image of the nervous system of a larval Cupelopagis vorax (Leidy, 1857) by Elizabeth Preza. Other winners of the image contest were Miloslav Devetter, Shuyu Gu, and Adán Jiménez Nigó (see volume cover; Platyias quadricornis).

As has been the practice for many of the previous meetings, this one was organized around a unifying theme. Because El Paso is located at an important nexus of Mexican and USA culture, the organizers chose a theme emphasizing this connection: "Crossing disciplinary borders in rotifer research." Within this general construct, several conference session themes were announced, each of which was anchored by one or two invited reviews and several contributions either in oral or poster sessions. Many notable results of the symposium are presented in this special issue of Hydrobiologia. As is the current tradition for the IRS, four guest editors - Steven Declerk (Netherlands), Diego Fontaneto (Italy), Rick Hochberg (USA), and Terry Snell (USA) - managed the peer review process for this special volume. The results of this congress were organized into five parts.

Part I, "Experimental Ecology" was opened by S. Nandini who presented an extensive review of the invertebrate predators on rotifers. Contributions published in this special volume focused on several aspects of rotifer behavior and on the development of

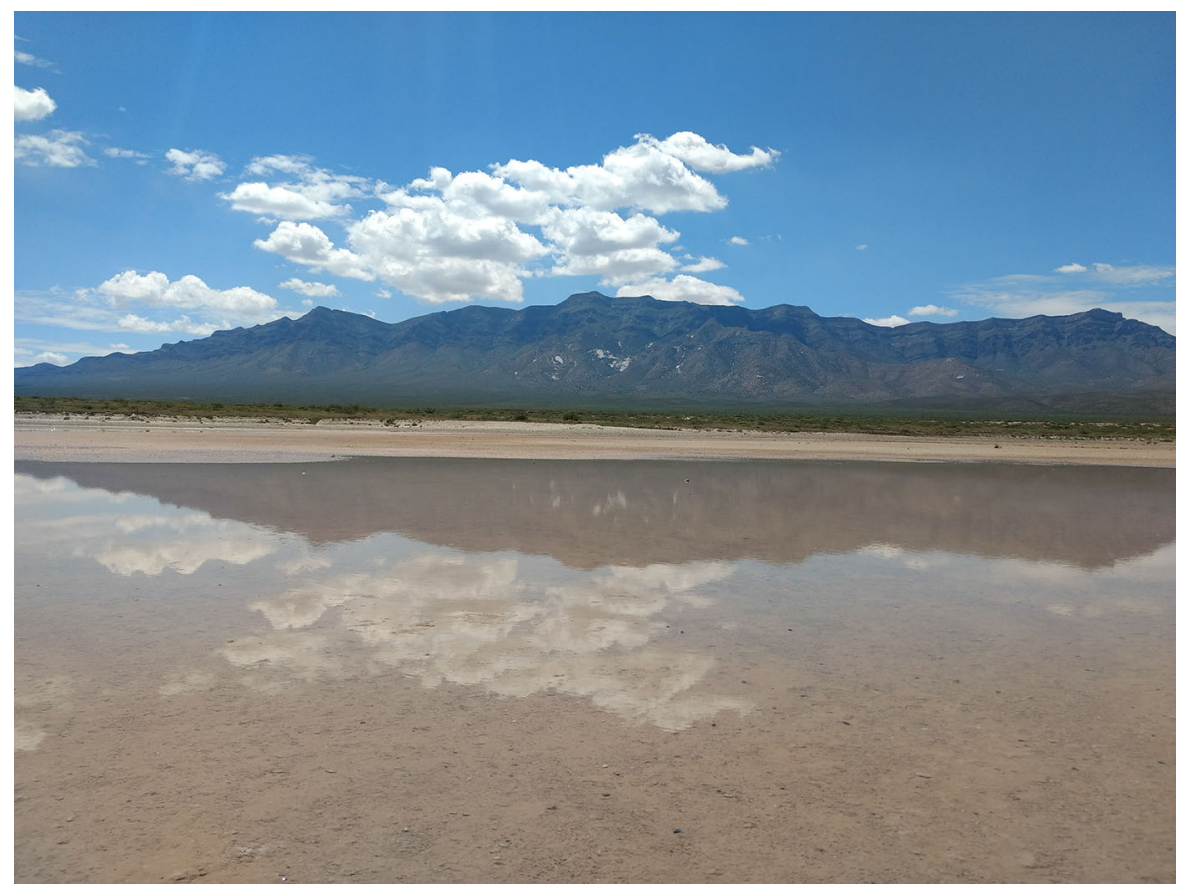

Fig. 2 White Sands National Monument (New Mexico). Lake Lucero during a wet phase. Photo credit: NPS, Patrick Martinez 

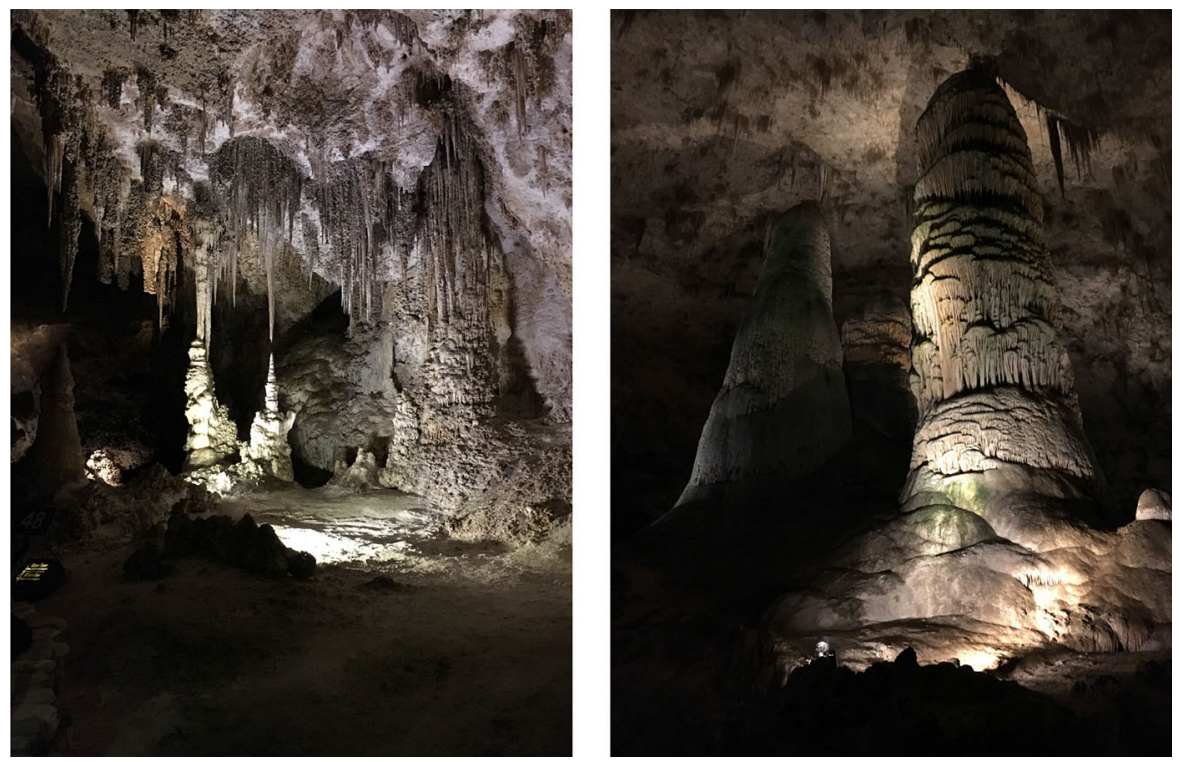

Fig. 3 Stalactites and stalagmites in Carlsbad Caverns National Park (New Mexico). Photo credit: Robert L. Wallace

an index to assess habitat trophic conditions. Allelochemicals are an important, if unseen, connection between species in aquatic systems. To explore one potential component of this connection, Gilbert (2019) studied the response of two strains of Brachionus rubens Ehrenberg, 1838 to a kairomone produced by the predatory rotifer Asplanchna brightwellii Gosse, 1850. In the presence of $A$. brightwellii or in Asplanchna-conditioned medium, B. rubens became a facultative epibiont attaching to the carapaces of Daphnia magna Straus, 1820. When Daphnia were absent, $B$. rubens aggregated on the bottom of culture vessels. This behavioral switch allowed $B$. rubens to avoid predation by $A$. brightwellii. Gilbert also demonstrated that induction of mixis in $B$. rubens was density-independent, thus at the high densities associated with being an epibiont the mictic cycle was not initiated. Another allelochemical connection was examined by Gama-Flores et al. (2019). They studied the effect of secondary metabolites released by three cladoceran species on three rotifer species (Brachionus havanaensis Rousselet, 1911, B. calyciflorus, and Plationus patulus Müller, 1786) and concluded that metabolites released by the cladocerans had weak allelopathic effects on the rotifers. Xi et al. (2019) conducted an interesting series of experiments to determine how Brachionus angularis Gosse, 1951 populations may adapt to an invading species, Brachionus calyciflorus Pallas, 1766 in the case of their study. They initiated a selection phase using treatments with and without invaders for 69 asexual generations. At the end of the experiment, $B$. angularis in the presence of the invader had higher growth rates than those without. Results of a common gardens experiment reinforced the conclusion that $B$. angularis is capable of rapid adaptation to the presence of $B$. calyciflorus. Using video analysis, Colangeli et al. (2019) examined the short-term, phototactic response of three rotifers, B. calyciflorus; Keratella cochlearis Gosse, 1851; Keratella quadrata (Müller, 1786), to UV radiation. Brachionus calyciflorus showed a strong negative response, while the two Keratella species exhibited weaker responses. Sarma \& Nandini (2019) proposed that the diverse and dense rotifer community present in hypereutrophic Lake Xochimilco (Mexico) is supported by seston. To test this hypothesis, they cultured six rotifers on three different size fractions of seston and found that these species appear to be able to coexist by partitioning the sestonic food supply. Using dynamic modeling, Young et al. (2019) examined how substratum selection by the larvae of sessile rotifers affects their fitness. Their models revealed that swimming speed, substratum preference, and coloniality were critical components to fitness. They also explored the conditions whereby planktonic, gnesiotrochan rotifers could 
survive. Stamou et al. (2019) tested the utility of commonly used indices of habitat trophic condition to see whether they applied to ponds in the Mediterranean climatic zone. Because the indices tested failed to correctly classify trophic status, the authors developed an improved index especially for eutrophic waterbodies.

Part II, "Genomic Approaches" featured two oral reviews by J.-S. Lee "Genomes of four Brachionus sp.: Applications in molecular and environmental genomics" and C.-P. Stelzer "Genome size evolution in rotifers." Advances using genomic approaches are highlighted in two manuscripts published in this volume. Brown \& Walsh (2019) used flow cytometry to investigate whether the genome size is correlated with lifestyle. They determined genome size for 13 gnesiotrochans rotifers that were sessile, colonial, or free-living. Genome size was greater in colonial taxa as compared to solitary species and sessile species had smaller genomes than free-swimming taxa. These findings will be beneficial for evolutionary and ecological studies, as well as informative as additional whole genomes of rotifers are sequenced. CRISPER/ Cas9 technology has provided a means to edit specific genes within organisms. One of the first published applications in rotifers is that by Kim et al. (2019). They successfully used this technology to mutate the cytochrome P450 3045C1 gene in Brachionus koreanus Hwang, Dahms, Park \& Lee, 2013. This technology has broad application to functional genomic studies in Rotifera.

Part III, "Long-term studies" had a single contribution. To glean insights from the responses of rotifers to large-scale and long-term environmental change, May \& Wallace (2019) undertook a meta-analysis of $>40$ papers that provided information on rotifer population dynamics over at least 10 years. While it is obvious that long-term research (LTR) is important as it provides insights to environmental drivers that cannot be recognized in short-term studies or by experiments, they observed that several critical research gaps remain unresolved. Chief among these are the following. Few LTR studies have been undertaken on rivers or in soil habitats, and studies including bdelloid rotifers are rare. In addition, most LTR studies have been done in Europe and North America; thus, a significant knowledge gap exists in our understanding of long-term patterns in Africa, Antarctica, and Australia.
Part IV, "Applied research." This session began with an oral review of "Bioconcentration of toxicants in rotifers" by R. Rico-Martínez. Applied research published in this special volume focused on ways of providing rotifers as food for target species and increasing rotifer population growth rates. New information on culture techniques were presented in four manuscripts published in this volume. Rearing finfish in culture necessitates that the gape size of their larvae be considered when considering the body size of live rotifers being offered as food. Unfortunately, it is difficult for hatcheries to maintain an array of rotifer species of different body sizes to accommodate these needs. Snell et al. (2019) describe how seven species within the genus Brachionus may be cultured and then their diapausing eggs be used as inocula so that the hatcheries can supply the fish larvae with rotifer prey having suitable body sizes. In their review, Hagiwara \& Marcial (2019) discuss utilization of rotifers outside of the Brachionus plicatilis Müller, 1786 species complex in rotifer aquaculture. Species that they considered to have a high potential for use in aquaculture are B. angularis, B. calyciflorus, and Proales similis Beauchamp, 1907. The remaining two contributions focused on members of the B. plicatilis species complex, one of the most widely used species in aquaculture. Kagali et al. (2019) investigated the potential enhancing properties of probiotics on the growth of Brachionus rotundiformis Tschugunoff, 1921. The two commercially available probiotics tested resulted in enhanced growth rates in the presence of an algal food source. We know that a range of pollutants impacts rotifer survival and reproduction. One that has received little attention is the emission of ethanol from ethanol-blended fuels. Udo et al. (2019) used a life-table approach to demonstrate that low levels of ethanol can actually extend the lifespan of individuals of $B$. plicatilis and potentially increase the number of young produced.

Part V, "Evolution." K. Gribble presented an oral review on the "Maternal effects on offspring fitness: rotifers as a model system for aging." A striking feature of rotifers, and the characteristic from which their names is derived, is the corona. Hochberg et al. (2019) undertook an in-depth analysis of collothecid corona and posited that it is not homologous to the corona of ploimid rotifers. Rather during metamorphosis from the larval stage to the adult, the corona is replaced by the infundibulum, which is derived from 
the larval foregut. The infundibulum thus represents a unique structure for food capture within this taxon. Another interesting structure present in some rotifers is birefringent bodies (BRB): small concretions with interesting optical properties. In their examination of BRB in gnesiotrochan rotifers, Yang et al. (2019) provided an updated survey of their presence and furnished the first data on their ultrastructure. The authors hypothesized that BRB are a unique form of glycogen, which functions as an energy source. Kordbacheh et al. (2019) provide an analysis of ecological differentiation among putative cryptic species of the littoral rotifer Euchlanis dilatata Ehrenberg, 1830. Previous work had identified substantial genetic variation among populations of the species. By analyzing a suite of traits, the authors were able to demonstrate reproductive isolation and life history variation among four lineages and described them as new species. The costs of sexual reproduction versus asexual reproduction are an on-going debate in evolutionary theory. Dimas-Flores et al. (2019) investigated whether sexually reproducing females compensate for that investment by changes in their survival and/or fecundity rates. Using a life-table approach, they did not find any correlation between the investment in sexual reproduction and the life history traits they measured. This supports the argument that sex is a costly strategy in B. plicatilis. Franch-Gras et al. (2019) reviewed bet-hedging strategies and diapause-related traits in populations of the $B$. plicatilis complex in Eastern Spain. They found that environmental unpredictability in growing season length acts as an effective selective pressure shaping diapause-related traits in these populations. The authors note the need for experimental evolution experiments along with more hypothesis-driven field observations.

In addition, three sessions offered updates on issues of special interest to rotiferologists. D. Fontaneto gave two overviews: one on the status of rotifer biodiversity: past, present, and future and another that provided an update on the Rotifera partim of the List of Available Names in Zoology. Two researchers gave invited reviews that examined the border between acanthocephalans and rotifers: O. Amin reviewed "Variability in the Acanthocephala" and H. Herlyn presented "Highly specialized rotifers: the inner and outer morphology of endoparasitic Acanthocephala."
Undeniably, there is no shortage of fundamental and appealing topics, each of which can lead to testable hypotheses that can be explored using stateof-the-art techniques using rotifers as model organisms. Below, we offer some examples that follow from talks at the 15th IRS.

We now know more about the relationship between acanthocephalans and rotifers, but we still need to explore the transition from the free-living life style of most Rotifera to obligatory parasitism in Acanthocephala. This is a life history boundary that has been crossed, but we do not know how this evolutionary step was accomplished. In addition, we still need to wed genomics and evolutionary developmental biology to achieve a better understanding of the relationship between these two groups, as well as across the phylum itself. Another cross-disciplinary topic in need of research is to assess how climate change leads to changes in biodiversity and community function. This could be achieved by LTR that focuses on a variety of ecological systems including rivers, soils, wetlands, and deserts, from both permanent and ephemeral systems. We can test hypotheses such as the importance of species change on food web and compensatory population dynamics, community resilience, and alterations in community re-assembly after a climate perturbation. As part of this research, studies need to employ various -omics (i.e., gen-, prote-, metabol-, connect-) to understand shifts in genetic structure, changes in gene expression, and other cellular responses. The application of CRISPR-Cas 9 technology will be very beneficial in understanding how specific mutations affect phenotype. Applied aspects of rotifer studies also have seen major advances. Our understanding of cryptic species in rotifers began when aquaculturists were puzzled by the number of morphologically similar strains of $B$. plicatilis. Now, emerging research indicates that the number of cryptic species may increase our understanding of rotifer biodiversity by at least tenfold and has added our knowledge of biogeographic patterns and ecological adaptations.

The future of rotifer research is not without some serious hindrances. The loss of competent taxonomists due death or the necessity that required them to switch careers is foremost among them. This is compounded by the fact that there is little opportunity for beginning students to become trained in taxonomy. To overcome this obstacle we need to develop solid educational 
platforms that can provide inexpensive, reliable instruction. More widespread recognition of the importance of rotifers and their use as model organisms is needed to attract a new generation of researchers, as well as funding for their research initiatives. We look forward to future gatherings of rotiferologists to discuss and find ways of meeting these challenges.

\section{In memoriam}

We dedicate this volume of rotifer research to the memory of María Rosa Miracle (1945-2017) (Fig. 4) host of the 6th International Rotifer Symposium that was held in Banyoles Spain in 1991. María Rosa's scientific interests were wide-ranging and covered both applied and theoretical topics. Indeed, it is difficult to summarize her interests, but they included varied subjects as cyanobacteria, algae, macrophytes, several taxa of zooplankton (including rotifers, of

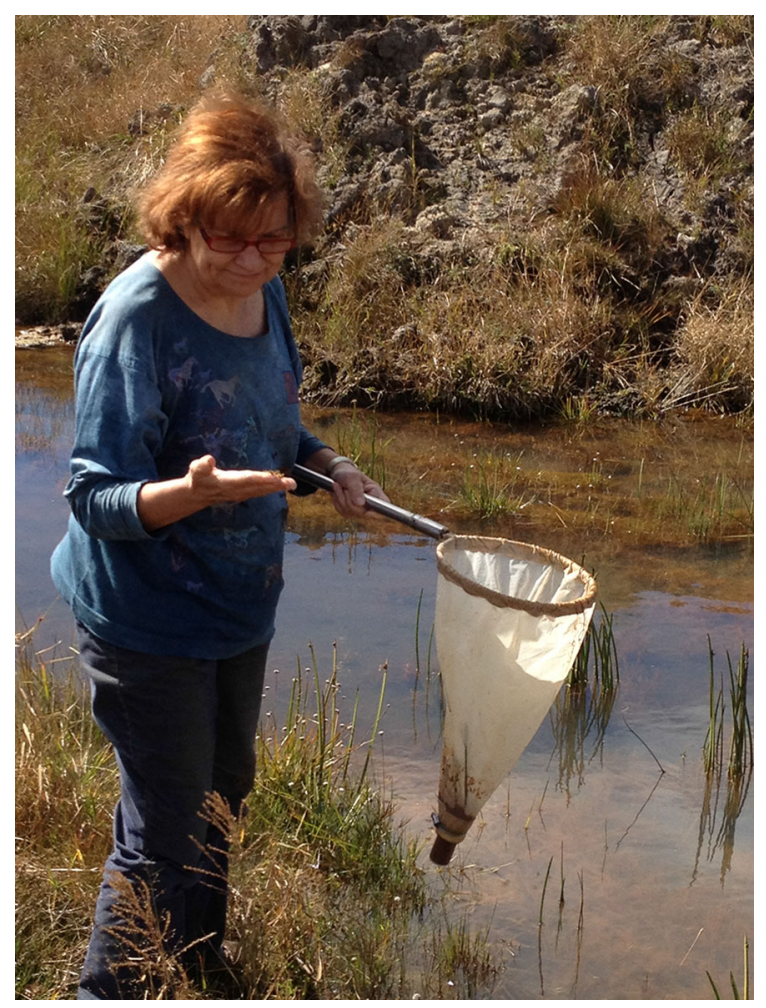

Fig. 4 Maria Rosa Miracle sampling during the 13th International Rotifer Symposium in India. Photo credit: Elizabeth J. Walsh course), shallow and meromictic lakes, coastal ponds, hypertrophic ponds, wetlands, paleolimnology, Pyrenean lakes, effects of climate change on zooplankton communities, lake management, and ecotoxicology. María Rosa's research on rotifers provided tests of ecological theories such as niche partitioning and effects of fishes and nutrient enrichments on zooplankton. María Rosa and her colleagues also studied rotifer phenotypic plasticity and aging, as well as effects of seasonality, oxygen concentration, salinity, temperature, and host-parasite relationships. Recently, many of her colleagues from around the world paid homage to her scientific intellect and curiosity by contributing scholarly papers to a volume of Limnetica that was dedicated in her honor (Camacho et al., 2019, and papers therein).

Acknowledgements We thank all the presenters and authors for their valuable contributions that made this symposium both enjoyable and intellectually stimulating. We especially thank the reviewers and guest editors for ensuring a high scientific standard of the studies published in this special issue. We are appreciative of Beto Lopez and UTEP's Offices of University Relations and Professional and Public Programs (P3) for their assistance in planning and executing the conference and thank Nicholas Houser, Perry Houser, Dr. Kevin Floyd, Helen Brewer, Josh Brown, Lara Barnes, and Beto Lopez for their willingness to serve as local tour guides for accompanying guests. David Bustos and Patrick Martinez from White Sands National Monument provided value help in coordinating and interpreting our visit to the Lake Lucero and the dune fields at the monument.

\section{References}

Brown, P. D. \& E. J. Walsh, 2019. Genome size and lifestyle in gnesiotrochan rotifers. Hydrobiologia. https://doi.org/10. 1007/s10750-018-3873-8.

Camacho, A., H. Dumont, S. S. S. Sarma, J. M. Soria \& E. Vicente, 2019. Preface. Limnetica 38(1): 1-9.

Colangeli, P., U. E. Schlägel, U. Obertegger, J. S. Petermann, R. Tiedemann \& G. Weithoff, 2019. Negative phototactic response to UVR in three cosmopolitan rotifers: a video analysis approach. Hydrobiologia. https://doi.org/10.1007/ s10750-018-3801-y.

Dimas-Flores, N., M. Serra, E. M. García-Roger \& M. J. Cormona, 2019. Evidencing the cost of sexual reproduction in the rotifer Brachionus plicatilis. Hydrobiologia. https:// doi.org/10.1007/s10750-019-3906-y.

Franch-Gras, L., E. Tarazona, E. M. García-Roger, M. J. Carmona, A. Gómez \& M. Serra, 2019. Rotifer adaptation to the unpredictability of the growing season. Hydrobiologia. https://doi.org/10.1007/s10750-019-3886-y.

Gama Flores, J. L., S. S. S. Sarma, A. N. López Rocha \& S. Nandini, 2019. Effects of cladoceran-conditioned medium 
on the demography of brachionid rotifers (Rotifera: Brachionidae). Hydrobiologia. https://doi.org/10.1007/ s10750-018-3853-z.

Gilbert, J. J., 2019. Attachment behavior in the rotifer Brachionus rubens: induction by Asplanchna and effect on sexual reproduction. Hydrobiologia. https://doi.org/10. 1007/s10750-018-3805-7.

Hagiwara, A. \& H. S. Marcial, 2019. The use of non-Brachionus plicatilis species complex rotifer in larviculture. Hydrobiologia. https://doi.org/10.1007/s10750-018-3837-z.

Hochberg, R., H. Yang, A. Hochberg, E. J. Walsh \& R. L. Wallace, 2019. When heads are not homologous: the coronae of larval and adult collothecid rotifers (Rotifera: Monogononta: Collothecaceae). Hydrobiologia. https:// doi.org/10.1007/s10750-018-3760-3.

Kagali, R. N., H.-J. Kim, T. Koga, Y. Sakakura \& A. Hagiwara, 2019. Effect of two commercial probiotic products on population growth of rotifer Brachionus rotundiformis Tschugunoff. Hydrobiologia. https://doi.org/10.1007/ s10750-018-3852-0.

Kim, D.-H., J. Yu, J. C. Park, C.-B. Jeong, S. Bae \& J.-S. Lee, 2019. Targeted cytochrome P450 3045C1 (CYP3045C1) gene mutation via CRISPR-Cas9 ribonucleoproteins in the marine rotifer Brachionus koreanus. Hydrobiologia. https://doi.org/10.1007/s10750-018-3854-y.

Kordbacheh, A., A. N. Shapiro \& E. J. Walsh, 2019. Reproductive isolation, morphological and ecological differentiation among cryptic species of Euchlanis dilatata, with the description of four new species. Hydrobiologia. https:// doi.org/10.1007/s10750-019-3892-0.

May, L. \& R. L. Wallace, 2019. An examination of long-term ecological studies of rotifers: comparability of methods and results, insights into drivers of change and future research challenges. Hydrobiologia. https://doi.org/10. 1007/s10750-019-04059-2.
Sarma, S. S. S. \& S. Nandini, 2019. Comparative population dynamics of six brachionid rotifers (Rotifera) fed seston from a hypertrophic, high altitude shallow waterbody from Mexico. Hydrobiogia. https://doi.org/10.1007/s10750018-3875-6.

Snell, T. W., R. K. Johnston \& A. B. Matthews, 2019. Utilizing Brachionus biodiversity in marine finfish larviculture. Hydrobiologia. https://doi.org/10.1007/s10750-018-3776-8.

Stamou, G., M. Katsiapi, M. Moustaka-Gouni \& E. Michaloudi, 2019. Trophic state assessment based on zooplankton communities in Mediterranean lakes. Hydrobiologia. https://doi.org/10.1007/s10750-018-3880-9.

Udo, T., P. S. Guissou, H. Ushio \& G. Kaneko, 2019. Ethanol extends lifespan of the rotifer Brachionus plicatilis. Hydrobiologia. https://doi.org/10.1007/s10750-018-37973.

Xi, Y.-L., K.-Q. Huang, L. Pan, H. Zhu, Y.-L. Ge, X.-L. Wen \& X.-L. Xiang, 2019. Rapid adaptation of Brachionus angularis (Rotifera) to invasion by Brachionus calyciflorus. Hydrobiologia. https://doi.org/10.1007/s10750019-3959-y.

Yang, H., R. Hochberg, E. J. Walsh \& R. L. Wallace, 2019. Systematic distribution of birefringent bodies in Rotifera and first evidence of their ultrastructure in Acyclus inquietus (Gnesiotrocha: Collothecaceae). Hydrobiologia. https://doi.org/10.1007/s10750-018-3784-8.

Young, A. N., R. Hochberg, E. J. Walsh \& R. L. Wallace, 2019. Modeling the life history of sessile rotifers: larval substratum selection through reproduction. Hydrobiologia. https://doi.org/10.1007/s10750-018-3802-x.

Publisher's Note Springer Nature remains neutral with regard to jurisdictional claims in published maps and institutional affiliations. 